\title{
ANALYSIS AND IDENTIFICATION OF SUBSYNCHRONOUS VIBRATION \\ FOR A HIGH PRESSURE PARALLEL FLOW CENTRIFUGAL COMPRESSOR
}

\author{
R.G. Kirk, J.C. Nicholas, G.H. Donald, and R.C. Murphy \\ Ingersol1 Rand Company \\ Easton, Pennsylvania 18042
}

SUMMARY

The evaluation of turbomachinery designs prior to actual hardware test and field installation is now the rule rather than the exception for rotating machinery manufacturers. This requires the verification of the current state of the art analytical techniques for rotor-bearing-seal dynamics by development testing and/or controlled test stand or field vibration studies. This paper presents the summary of a complete analytical design evaluation of an existing parallel flow compressor and reviews a recent field vibration problem that manifested itself as a subsynchronous vibration that tracked at approximately $2 / 3$ of compressor speed. The comparison of predicted and observed peak response speeds, frequency spectrum content, and the performance of the bearing-seal systems are presented as the events of the field problem are reviewed. Conclusions and recommendations are made as to the degree of accuracy of the analytical techniques used to evaluate the compressor design.

\section{INTRODUCTION}

The design of dependable turbomachinery has always been of utmost importance in natural gas pipeline and petro-chemical installations. To meet this challenge it is necessary for the designer of the turbomachinery to utilize state of the art aerodynamic and mechanical vibration analytical prediction capabilities. Tremendous advances have been made in the past ten years in these areas (ref. 1-8). Improved data retrieval and data reduction equipment make it possible for mechanical vibration and aerodynamic pressure levels to be monitored to assist in test stand design verification and/or the solution of field problems in the event that they should occur (ref. 9-12). The correlation of predicted to actual system behavior has been less than desirable in the area of rotor-bearing system stability. This is especially true in regards to the prediction of levels of destabilizing forces and the self-excited whirl frequencies. It has generally been the rule that actual whirl frequencies are higher than predicted frequencies for turbocompressors. Further complications arise when the exact source or characteristic of an excitation cannot be categorized relative to prior operating behavior of turbocompressors.

The following paper will document such an occurrence for a particular design configuration of a single-stage, parallel flow compressor in a gas transmission facility. The summary of the compressor rotor dynamics analysis will be presented in addition to selected field data taken to characterize the vibration before and after a successful field redesign to eliminate the source of the nonsynchronous excitation. 
Values are given in both SI and U.S. Customary Units. The measurements and calculations were made in U.S. Customary Units.

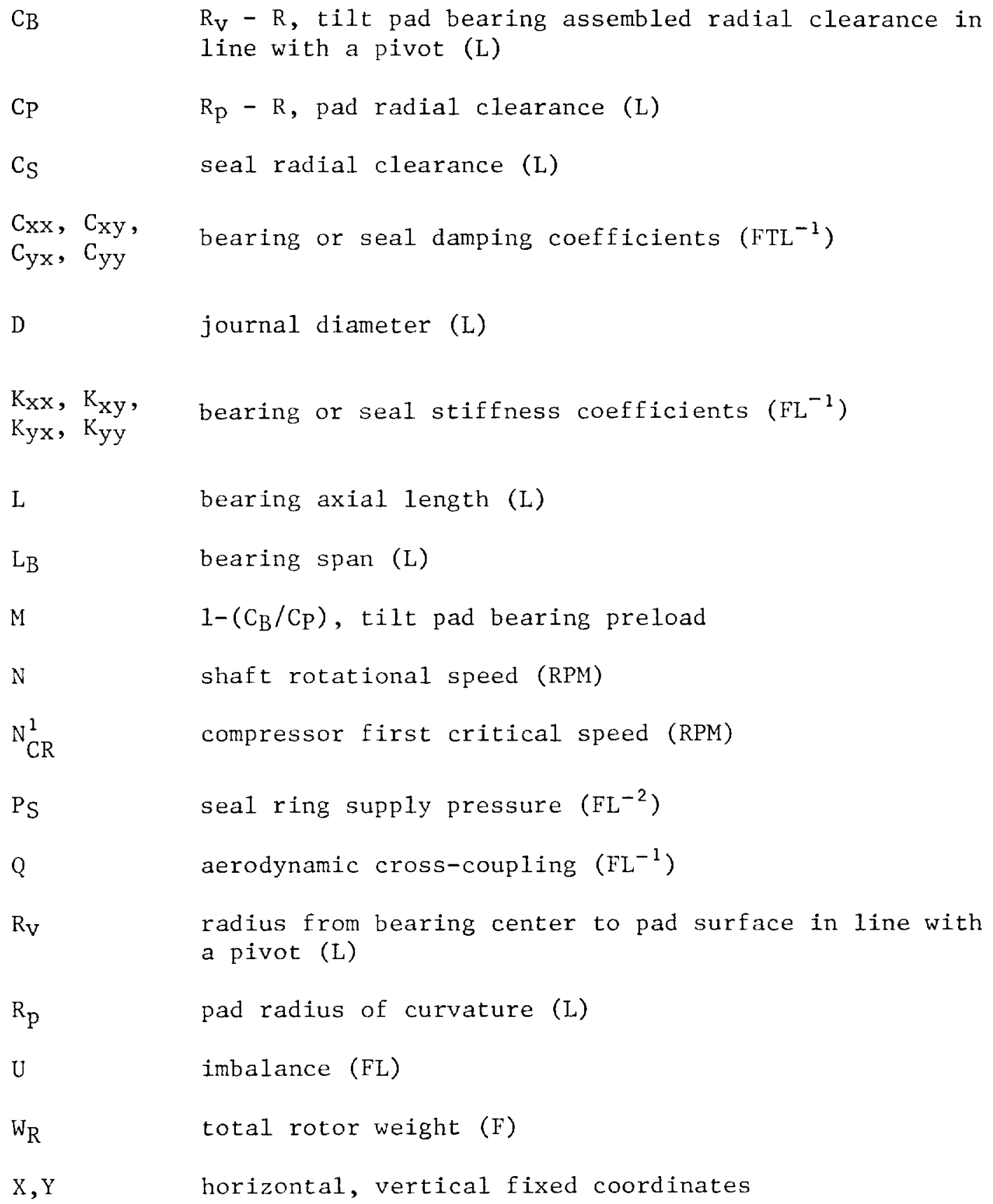


The compressors that are the basis for this paper are similar to over 80 units in operation throughout the world with the same basic shaft and bearing configuration. The compressors are driven through a flexible gear coupling by an Ingersoll-Rand GT-22 power turbine which is rated at up to $4250 \mathrm{H} . \mathrm{P}$. at a max speed of 14,500 RPM. The units under discussion consist of 6 separate compressors that may be operated either in series or isolated for closed loop evaluation. The compressor configuration is shown in fig. 1 for parallel flow operation. The rotor is supported on preloaded 5-shoe tilting pad bearings with high pressure oil seal rings just inboard of the bearings as shown in fig. 2. l'he bearings are fed from the discharge of the outer seal ring and hence the seals and bearings have a common lube oil system. All six units are designed for purge gas injection for sour gas service while only three are typically utilized for this service. The bearing and seal housings are close tolerance double cartridge design to facilitate assembly and disassembly. The high pressure loading locks the cartridge with several tons of axial loading and thus assures a rigid interface to the compressor casing. The compressor rotor stage configuration is indicated in fig. 3 where the parallel flow stages are shown with the vaneless diffuser in cross-section. The stages are balanced aerodynamically at inlet and discharge as a result of system symmetry about the center diffuser ring.

Three of the compressors have been in service since 1973 with no major vibration problem encountered prior to the spring of 1979 . Tripout due to surge related phenomena had occurred but the units were always capable of restart without incident. Two additional units were shipped in late 1974 and the sixth in mid-1978. The units will be denoted as 1-6. Unit Number 5 experienced vibration problems at high speed and load which necessitated several rebuilds, from December 1978 through May 1979, associated with coupling adjustments, impeller fits, and bowed rotor induced imbalance. The rotor was locked in a 13 mil bow on one occasion which came straight upon disassembly. Rubs were noted on the latter runs of this unit.

Compressor Number 6 had been damaged on commissioning via foreign object ingestion resulting in excessive vibration and rubbing on the impeller rims.

Compressor Number 2 had sustained damage in the seal area due to a lack of cleanliness during reassembly which required that the shaft be built up by chrome deposition in the seal area. Upon retrofit this unit began experiencing vibration tripouts at high speed and load, but was capable of restart. As of May 1979 two of the units, Nos. 1 and 3, were capable of continuous operation without limitation, one of which had not been disassembled since shipment in 1973. Two units, Nos. 2 and 5, were experiencing tripouts but could be restarted. The remaining units, Nos. 4 and 6 , would vibrate such that restart was questionable. This fact, being unsatisfactory to the customer and IngersollRand, prompted action including analytical studies of the existing design using latest analytical techniques, documentation of vibration and pulsation data on site by both IR and consultants, and the examination of potential retrofit designs for the rotor-bearing-seal system. 
Vibration data had been taken and reduced in March of 1979 that revealed a 2/3 rotative speed component of vibration that tracked with speed and came into coincidence with another fixed frequency component at a frequency of approximately $140 \mathrm{~Hz}$. This is shown in $\mathrm{fig} .4$ where the $2 / 3$ component is noted to appear above $200 \mathrm{~Hz}(12,000 \mathrm{cpm})$ rotor speed. The distinct frequencies are shown more clearly in fig. 5 where the $2 / 3$ component is coming into coincidence to the fixed frequency. This figure does not have the line frequency $(50 \mathrm{~Hz})$ and $3 \mathrm{X}$ line frequency interference as noted on the earlier data given in fig. 4 .

The forced response for the same No. 6 Unit is given in fig. 6 for the coupling and thrust end probe locations. This startup had a sequenced pressurization and fast accel through the critical of approximately $124-129 \mathrm{~Hz}$. The units were typically started under full pressure which raised the peak response frequency to $130-140 \mathrm{~Hz}$ as a result of the increased stiffness and damping from the seal rings. This influence is indicated by the traces given in $\mathrm{fig} .7$ plotted for a portion of the accel. It is noted that the scales of figs. 6 and 7 are not all the same but the values of peak amplitude and frequency noted on the traces were read from an RTA and give an accurate indication of the peak response frequencies and amplitudes.*

SUMMARY OF ROTOR DYNAMICS ANALYSIS

The vibration problem as described in the previous section had not been documented by any reference that was available to the knowledge of IngersollRand or numerous consultants contacted concerning the nature of the field problem (ref. 14-20). The obvious potential sources - motors, pumps, power takeoffs gas generator, etc., were investigated without a valid mechanical element in the overall system design that could give the $2 / 3$ x compressor speed forcing function. The thrust of the initial analytical investigation was therefore to conclude what could be modified in the bearing-seal system to improve the response and stability of the compressor. This procedure was less desirable than eliminating the source of the excitation, but at that time the source was unknown.

The compressor was analyzed by in-house computer programs for bearing analysis (ref. 5), seal dynamics (ref. 4), rotor response (ref. 13), and system dynamic stability (ref. 7). The compressor shaft was initially modeled neglecting the impeller shrink fits, which is in general the most conservative design technique since added stiffness typically improves stability.

The undamped critical speed map for the $160 \mathrm{lb}$. rotor is given in $\mathrm{fig} .8$ including and neglecting the potential impeller fit stiffness. The fits were more likely to add stiffness since the design was keyless and the fit was necessary to transmit the horsepower. Fig. 8 indicates that the first critical can be raised as much as $17 \mathrm{~Hz}(\sim 1000 \mathrm{cpm})$ by the impeller fit since the midspan position of the fits have a large influence on the first mode. Overplotted on this map are the bearing characteristics for the minimum and approximate maximum clearance for the current bearing design to be referred to as the new design.

* All experimental data presented in this report was very capably taken and reduced by Mr. Terry Mitchell of Ingersol1-Rand, Wythenshawe, England. 
The original units were shipped with a shorter pad and are referred to as the old design. The properties of these designs are given in table 1 for reference. Three compressors had the old design and three the new, but no correlation existed between bearing type and severity of vibration. The unit with the longest trouble-free operation had the old design bearings. However, another unit, No. 5, exhibited strong instability with the old design. The results of the analysis indicated the old design to be less desirable for stability. Since all current units utilize the new design, the analytical results herein are for the new bearing design.

The rotor system was modeled including the influence of the oil ring seals under design pressure and temperature conditions. For example, table II gives the characteristics for the outer seal at $\mathrm{N}=208 \mathrm{~Hz}(12,500 \mathrm{RPM})$ for a suction pressure of 1000 psi.

Compressors having covered stages are considered to have little or no destabilizing aerodynamic cross-coupling. The compressor stability or growth factor is plotted in fig. 9 and indicates that a total level of over 10,000 1b/in could be tolerated for nominal design conditions without excessive excitation. The basic design has proven very stable in applications having more stages and hence higher design to 1st peak response speed ratios. Classical aerodynamic excitation is not known to be characterized by a tracking component.

Figure 10 presents the stability of the compressor as a function of bearing preload. The solid curve is the new design and the preload range of 0.55 to 0.7 is indicated to be acceptable. It should be noted that when the bearings were designed the capability to predict stability was not available and hence the judgement indicates good design practice. The dashed line has a better optimum stability and a preload range of 0.24 to 0.52 will result in the optimum bearing configuration. This design is referred to as the redesign bearing (see table I).

The response of the coupling end bearing is plotted in fig. 11 for a range of bearing clearances showing that the compressor can experience a peak response, ranging from $108 \mathrm{~Hz}$ (6500 RPM) to $137 \mathrm{~Hz}$ (8200 RPM) depending on the actual build clearances in the compressors.

The influence of the seals on the response is indicated in fig. 12. For centered sea1s a single peak response at $112 \mathrm{~Hz}(6700 \mathrm{RPM})$ is indicated whereas the more likely response would appear as a double peak with peaks occurring in the range of $115 \mathrm{~Hz}-145 \mathrm{~Hz}$ (6900 RPM-8700 RPM) without any account of impeller stiffness.

The influence of the seals' eccentricity on system damped natural frequencies and stability is shown in fig. 13. The eccentric seal is noted to split the 1st mode from $2.8 \mathrm{~Hz}(168 \mathrm{cpm})$ to $26 \mathrm{~Hz}(1567 \mathrm{cpm})$ for maximum pressure at startup. The frequencies vary as a function of speed as indicated in fig. 14. It is noted that one damped critical tracks with little change in frequency at near $130 \mathrm{~Hz}(7800 \mathrm{cpm})$ while the lower damped critical also remains reasonably fixed in frequency but becomes less stable at higher speeds. While the higher frequency mode is indicated to be backward, the response study of fig. 15 clearly illustrates that both these modes are excited by a forward 
rotating excitation for bearing and seal characteristics fixed at values for $\mathrm{N}=225 \mathrm{~Hz}(13,500 \mathrm{RPM})$ whereas on runup the only mode excited is the higher (backward) mode.

A summary of the bearing optimization study is presented in figs. 16 and 17 for the new and redesign bearings (reference table I). The forward modes are noted to optimize for the nominal redesign bearings with a seal ring groove, whereas the new bearing design is best for the condition of no seal ring groove. Further, while the redesign bearings can be optimized, the potential oversize clearance condition is indicated to be more severe for the redesign bearings.

The results of a stability study, wherein the rotor system was artificially stiffened to match the forward mode to the $140 \mathrm{~Hz}$ frequency are presented in figs. 18 and 19 for the new and redesign, nominal bearing conditions. The plots are given as growth factor versus aerodynamic excitation with the conclusion being that the redesign nominal condition is far superior to the new bearing design. The stabilizing influence of the seals on system stability is also indicated by these plots. This is characteristic of rotors operating below 2.2 times the rotor first peak response frequency (ref. 4).

Consideration was given, following recommendations from the customer, to possib1y overboring the impeller and retrofitting a larger diameter shaft in an attempt to improve the overall system rotor dynamics. The compressor design is now and was always considered to be acceptable for normal. levels of aerodynamic excitation. The present design is noted to be at a $N / N$ cr ratio of less than 1.7 which puts this compressor out of the class of the original Kaybob $\left(\mathrm{N} / \mathrm{N}_{\mathrm{Cr}} \sim 2.8\right)$ and Ekofisk $\left(\mathrm{N} / \mathrm{N}_{\mathrm{Cr}} \sim 2.2\right)$ designs (see refs. 9 and 11$)$. It is noted that the Ekofisk redesign shaft moved the critical from $48 \%$ to $66 \%$ of rated speed. The present design places the critical at $60 \%$ of design speed.

With this background the concept of a stiffer shaft for the compressor seems inconsistent with past experience. An improvement in stability is predicted as would be expected but the once-per response levels and minimum speed range would be greatly influenced as noted by the response results of fig. 20 . These response levels may be scaled linearly to approximately 2.0 mils for increased levels of imbalance. It is evident that the once-per response level at $13,000 \mathrm{rpm}$ wi.11 be increased by $255 \%$ for nominal bearing clearances with the peak response speed occurring as high as $11,000 \mathrm{rpm}$.

With the above facts indicating a very possible degradation of design speed response and only a marginal improvement in stability, the concept of the stiffer shaft was considered as an absolute last resort redesign consideration.

The following section will summarize the redesign steps and results that paralleled the analytical studies briefly reviewed in this section. 


\section{SUMMARY OF FIELD MODIFICATIONS AND CONCLUSIONS OF OUTSIDE CONSULTANTS}

The analytical study summarized in the previous section was paralleled with field modifications and discussions with major turbomachinery consultants. The basic conclusion of the consultants was that the analytical studies were state of the art and only selected checks were run on the basic model to confirm the results. In addition, no occurrence of the $2 / 3$ tracking phenomena was known to any of the consultants engaged.

Initial field variations in hardware consisted of changing out rotors and impellers to assure that an impeller blade rework to remove a casting problem on the leading edge blades of the original compressor stages was not responsible for the superior response of the original units. No correlation was found to this small difference and the severe tripouts.

As mentioned previously, the original units were fitted with shorter, lower preload bearings but no correlation could be made relative to bearing type and the sensitivity to the nonsynchronous excitation.

The analysis indicated that removing the circumferential groove from the outer seal ring would improve the dynamic performance. This was tried and the result was affirmative but not sufficient to control the nonsynchronous forcing mechanism.

Prior test stand experience indicated light rubs could reexcite the first critical on this type compressor. For this reason, and since deep grooving was noted in the buffer gas laby babbitted surface, the laby clearance was increased to assure that no rub was occurring before tripout. After the laby clearance was increased, the compressor spectrum was noted to be substantially cleaner but the $2 / 3$ component was still present and the units were speed limited.

As mentioned earlier, the stages were not keyed but relied on the shrink fit for torque transmission. Some concern existed for a possible internal friction mechanism at the impeller-shaft interface since these fits were at midspan, the most sensitive position for reexcitation of the 1 st critical. Also of concern, but without any analytical grounds for verification, was the stage spacing and the design of the center ring diffuser (see fig. 3). These concerns were overshadowed by possible excitation from reflected pressure pulsation from either inlet or discharge (see fig. 1) and the potential for a rotating stall cell in the inlet or rotating stall in the vaneless diffuser.

The latter concerns were proven to be of no consequence by dynamic pressure pulsation data taken in the piping, the inlet area of the stages, and the diffuser. No evidence of pulsations that tracked or correlated to the vibration was detected in the No. 5 compressor instrumented with internal dynamic pressure transducers. Additional piping pressure pulsation data were taken on other units without any correlation to the forcing frequency.

At the same time an order was placed for the redesign bearing, the No. 6 compressor was modified to a keyed shaft with reduced fits, and the center diffuser inside diameter was dropped to improve stage isolation. Additionally, 
the cavity was pressurized to force flow radially up the back sides of the stages. The result of this modification was the elimination of the $2 / 3$ forcing frequency. Upon replacement with an original impeller shaft configuration the $2 / 3$ component was still absent.

At this time the redesign bearings were tried in compressor No. 5 in addition to another trial of the old style bearings. The critical was noted to drop in speed from $135 \mathrm{~Hz}(8100 \mathrm{RPM})$ to $122 \mathrm{~Hz}$ (7350 RPM) after a shutdown and immediate restart. As much as $0.25 \mathrm{mil}$ subsynchronous was still present at a frequency of $130 \mathrm{~Hz}(7800 \mathrm{cpm})$.

\section{RESULTS OF FINAL DESIGN MODIFICATIONS}

The events of the field retrofits and analysis resulted in a decision to use the original, keyless shaft with the new bearing design and grooveless seal rather than the redesign bearings and grooved seal. In addition, the diffuser was dropped and the center cavity pressurized to discharge pressure. This configuration was installed in two other compressors in addition to No. 6 (No. 2 and No. 5) with the result being the elimination of the $2 / 3$ component and only a very small level of fixed frequency sub-synchronous vibration $(0.05 \mathrm{mil} \max$. typical). The No. 2 compressor was speed limited due to balance, initially. When this was corrected, the speed limit was removed. Al1 units were then capable of going the full speed range without encountering sub-synchronous vibration levels in excess of acceptable or tolerable levels. The compressors with the modified diffusers have no $2 / 3$ component while the unmodified compressors are not speed limited, but do have a small $2 / 3$ component that is detectable but remains bounded.

The frequency spectrum before and after the final design modification for compressor No. 5 is given in figs. 21 and 22 , respectively. The improved low level of fixed frequency is acceptable to both Ingersoll-Rand and the customer.

\section{CONCLUSIONS}

The following conclusions have been reached from a critical review of the design evaluation and field vibration performance of the six single-stage, parallel flow compressors discussed in this report:

1. Complex turbomachinery can be modeled to the necessary accuracy to study response sensitivity if all impeller fits, bearing clearances, seal clearances, and balance levels are known.

2. It is practical to do a design optimization to study design variation trends without achieving exact agreement between predicted and actual measured levels for damped frequencies.

3. Achieving bearing optimization in production bearings requiring less than $1 / 2 \mathrm{mil}$ total variation in radial clearance at assembly is impractical and impossible to achieve in reality. 
4. Compressors having oil seals and tilting pad bearings should have the bearing designed with a minimum preload value greater than about $30 \%$ for the best stability characteristics.

5. Zero or low preload tilting shoe bearings used in compressors having oil seals are more susceptible to oil seal or aerodynamic excited shaft whip than higher preload designs.

6. High pressure compressors utilizing oil seals and operating below 2.2 $2.5 \times \mathrm{N}_{\mathrm{cr}}^{1}$ can have increased stability and improved forced response sensitivity with eccentric seals as compared to centered seals.

7. Oil seals can alter the peak response speed of compressors by as much as

$30 \mathrm{~Hz}$ with likely variation during startups on the order of $10 \mathrm{~Hz}$.

8. Both forward and backward analytically predicted damped natural modes can

be excited by forward rotative forcing mechanisms.

9. Compressors operating below $1.8 \times \mathrm{N}_{\mathrm{cr}}^{1}$ cannot have substantial improvements in overall dynamic sensitivity by increasing the rotor shaft stiffness. This is especially true when a speed range is desirable from 80-100\% design speed, for instance.

10. A forcing function mechanism has been proven to occur in parallel flow compressors due to the spacing and flow of high pressure gas in the space and on the back sides of the double flow stages. The detected mechanism produced a $2 / 3 \times$ compressor speed excitation that can produce large level subsynchronous vibration when this frequency of excitation coincides with a system natural frequency.

11. A successful solution to the $2 / 3 \mathrm{x}$ speed forcing component was arrived at by combined field tests, analytical work, and engineering judgement.

\section{REFERENCES}

1. Lund, J.W., "Stability and Damped Critical Speeds of a Flexible Rotor in Fluid-Film Bearings", Journal of Engineering for Industry, Trans. ASME, Series B, Vo1. 96, No. 2, May 1974, pp. 509-517.

2. Lennemann, E., and Howard, J.H.G., "Unsteady Flow Phenomena in Rotating Centrifugal Impeller Passages", Journal of Engineering for Power, Trans. ASME, January, 1970, pp. 65-72.

3. Dussourd, J.L., et al, "An Experimental Investigation of the Control of Surge in Radial Compressors Using Close Coupled Resistances", Journal of Fluids Engineering, Trans. ASME, March, 1977, pp. 64-75.

4. Kirk, R.G., and Miller, W.H., "The Influence of High Pressure Oil Seals on Turbo-Rotor Stability," ASLE Trans., Vo1.22, No.1, Jan. 1979, pp. 14-24.

5. Nicholas, J.C., Gunter, E.J., and Barrett, L.E., "The Influence of Tilting Pad Bearing Characteristics on the Stability of High Speed Rotor-Bearing Systems," Topics in Fluid Film Bearing and Rotor Bearing System Design and Optimization, an ASME special publication, April 1978, pp. 55-78.

6. Lund, J.W., "Modal Response of a Flexible Rotor in Fluid-Film Bearings", Journal of Engineering for Industry, Trans. ASME, Series B, Vo1. 96, No. 2, May 1974, pp. 525-533. 
7. Kirk, R.G., "Stability and Damped Critical Speed - How to Calculate and Interpret the Results", CAGI, Technical Digest, Vol. 12, No. 2.

8. Nicholas, J.C., and Kirk, R.G., "Selection and Design of Tilting-Pad and Fixed Lobe Journal Bearings for Optimum Turborotor Dynamics", Proceedings of the 8th Turbomachinery Symposium, Texas A\&M University, College Station, Texas, 1979, pp. 43-57.

9. Smith, K.J., "An Operation History of Fractional Frequency Whir1," Proceedings of the Fourth Turbomachinery Symposium, Texas A \& M University, College Station, Texas, 1975, pp. 115-125.

10. Wache1, J.C., "Nonsynchronous Instability of Centrifugal Compressors", ASME Paper 75-Pet-22, Presented at Petroleum Mechanical Engineering Conference, Tulsa, Oklahoma, Sept. 21-25, 1975.

11. Booth, D., "Phillips' Landmark Injection Project", Petroleum Engineer, Oct. 1975, pp. 105-109.

12. Sparks, C.R., and Wachel, J.C., "Pulsations in Liquid Pumps and Piping Systems", Proceedings of the 5 th Turbomachinery Symposium, Texas A \& M University, College Station, Texas, 1976, pp. 55-61.

13. Lund, J.W., "Rotor Bearing Dynamics Design Technology, Part V", AFAPL-TR65-45, Aero Propulsion Laboratory, Wright-Patterson Air Force Base, Ohio, May 1965.

14. Jansen, W., "Steady Fluid Flow in a Radial Vaneless Diffuser", Journal of Basic Engineering, Trans. ASME, Series D, Vol. 86, 1964, pp. 607-619.

15. Jansen, W., "Rotating Sta11 in a Radial Vaneless Diffuser", Journal of Basic Engineering, Trans. ASME, Series D, Vol. 86, 1964, pp. 750-758.

16. Alford, J.J., "Protecting Turbomachinery from Self-Excited Rotor Whirl", Journal of Engineering for Power, Trans. ASME, Series A, Vo1. 87, Oct. 1965, pp. 333-344.

17. Nicholas, J.C., Gunter, E.J., and Allaire, P.E., "Stiffness and Damping Coefficients for the Five-Pad Tilting-Pad Bearing", ASLE Trans., Vol. 22, No. 2, April 1979, pp. 113-124.

18. Black, H.F., "The Stabilizing Capacity of Bearings for Flexible Rotors with Hysteresis," Journal of Engineering for Industry, Trans. ASME, Feb. 1976, pp. 87-91.

19. Kirk, R.G., and Gunter, E.J., "Non-Linear Transient Analysis of Multi-Mass Flexible Rotors - Theory and Application", NASA CR-2300, Sept. 1973.

20. Ferrara, P.L., "Vibrations in Very High Pressure Centrifugal Compressors", ASME Preprint 77-DET-15, Presented at Design Engineering Technical Conference, Chicago, I1linois, Sept. 26-30, 1977. 


\begin{tabular}{|c|c|c|c|c|c|c|c|}
\hline \multirow[b]{2}{*}{ Bearing } & \multirow[b]{2}{*}{$\begin{array}{l}\mathrm{L} \\
1 \mathrm{n} \\
(\mathrm{cm})\end{array}$} & \multirow[b]{2}{*}{$\begin{array}{c}C_{B} \\
\text { mils }\left(\operatorname{mrn} \times 10^{-2}\right)\end{array}$} & \multirow[b]{2}{*}{$M$} & \multicolumn{4}{|c|}{$\mathbf{N}=12,500 \mathrm{RPM}$} \\
\hline & & & & $\begin{array}{c}\mathrm{K}_{\mathrm{XX}} \times 10^{-5} \\
1 \mathrm{~b} / \mathrm{in}(\mathrm{N} / \mathrm{cm})\end{array}$ & $\begin{array}{c}\text { kyy } \times 10^{-5} \\
1 \mathrm{~b} / \mathrm{in}(\mathrm{N} / \mathrm{cm})\end{array}$ & $\begin{array}{c}\mathrm{C}_{\mathrm{XX}} \\
\mathrm{lb}-\mathrm{s} / \mathrm{ln}(\mathrm{N}-\mathrm{s} / \mathrm{cm})\end{array}$ & $\begin{array}{c}\mathrm{c}_{y y} \\
\mathrm{lb}-\mathrm{s} / \mathrm{fn}(\mathrm{N}-\mathrm{s} / \mathrm{cm})\end{array}$ \\
\hline New & $\begin{array}{l}1.375 \\
(1.49)\end{array}$ & $\begin{array}{l}1.400(3.36) \text { Min } \\
1.775(4.51) \text { Nom } \\
2.150(5.46) \text { Max }\end{array}$ & $\begin{array}{l}.70 \\
.62 \\
.55\end{array}$ & $\begin{array}{l}7.86(13.76) \\
4.31(7.55) \\
2.57(4.50)\end{array}$ & $\begin{array}{l}7.96 \quad(13.94) \\
4.43 \quad(7.76) \\
2.68 \quad(4.69)\end{array}$ & $\begin{array}{ll}433 & (758) \\
291 & (510) \\
205 & (359)\end{array}$ & $\begin{array}{ll}436 & (764) \\
295 & (517) \\
209 & (366)\end{array}$ \\
\hline old & $\begin{array}{l}1.000 \\
(2.54)\end{array}$ & $\begin{array}{l}2.000(5.08) \text { Min } \\
2.375(6.03) \text { Nom } \\
2.750(6.99) \text { Max }\end{array}$ & $\begin{array}{l}.52 \\
.40 \\
.27\end{array}$ & $\begin{array}{l}1.63(2.85) \\
.887(1.55) \\
.499(0.87)\end{array}$ & $\begin{array}{r}1.88(3.29) \\
1.20(2.10) \\
.90(1.58)\end{array}$ & $\begin{aligned} 131 & (229) \\
98 & (172) \\
76 & (133)\end{aligned}$ & $\begin{array}{r}142(249) \\
114(200) \\
99(174)\end{array}$ \\
\hline Redes $i g n$ & $\begin{array}{l}1.375 \\
(3.49)\end{array}$ & $\begin{array}{l}1.900(4.83) \mathrm{Min} \\
2.275(5.78) \mathrm{Nom} \\
2.650(6.73) \mathrm{Max}\end{array}$ & $\begin{array}{l}.52 \\
.38 \\
.24\end{array}$ & $\begin{array}{l}3.14(5.50) \\
1.62(2.84) \\
.785(1.37)\end{array}$ & $\begin{array}{ll}3.27 & (5.73) \\
1.76 & (3.08) \\
.979 & (1.71)\end{array}$ & $\begin{array}{ll}277 & (485) \\
204 & (357) \\
159 & (278)\end{array}$ & $\begin{array}{ll}283 & (496) \\
212 & (371) \\
172 & (301)\end{array}$ \\
\hline
\end{tabular}

$\begin{array}{ll}D=2.75 \mathrm{in}(6.985 \mathrm{~cm}) & \mathrm{L} / \mathrm{D}=1 / 2(\text { New, Redesign }) \\ W_{R}=160 \operatorname{lbs}(711.7 \mathrm{~N}) & \mathrm{L}_{\mathrm{B}}=33 \mathrm{in}(83.82 \mathrm{cri})\end{array}$

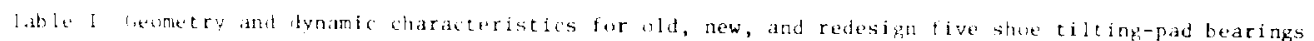

\begin{tabular}{|c|c|c|c|c|c|}
\hline Seal & $\begin{array}{c}\mathrm{K}_{\mathrm{xy}} \times 10^{-5} \\
1 \mathrm{~b} / \mathrm{in} \\
(\mathrm{N} / \mathrm{cm})\end{array}$ & $\begin{array}{c}\mathrm{K}_{\mathrm{yx}} \times 10^{-5} \\
1 \mathrm{~b} / \mathrm{in} \\
(\mathrm{N} / \mathrm{cm})\end{array}$ & $\begin{array}{c}\mathrm{C}_{\mathbf{x x}} \\
(1 \mathrm{~b}-\mathrm{s} / 1 \mathrm{n}) \\
(\mathrm{N}-\mathrm{s} / \mathrm{cm})\end{array}$ & $\begin{array}{c}\mathrm{C}_{y y} \\
(1 \mathrm{~b}-\mathrm{s} / \mathrm{in}) \\
(\mathrm{N}-\mathrm{s} / \mathrm{cm})\end{array}$ & $\begin{array}{c}\text { Lock-up } \\
\text { Eccentrlctey }\end{array}$ \\
\hline w/groove & $\begin{array}{c}7.86 \\
(13.76)\end{array}$ & $\begin{array}{c}-1.12 \\
(-1.96)\end{array}$ & $\begin{array}{c}171 \\
(299)\end{array}$ & $\begin{array}{c}1460 \\
(2557)\end{array}$ & .84 \\
\hline w/o groove & $\begin{array}{c}4.85 \\
(8.49)\end{array}$ & $\begin{array}{l}-2.03 \\
(-3.55)\end{array}$ & $\begin{array}{c}310 \\
(543)\end{array}$ & $\begin{array}{c}717 \\
(1256)\end{array}$ & .55 \\
\hline
\end{tabular}

$$
\begin{array}{ll}
\mathrm{K}_{\mathrm{xx}}=\mathrm{K}_{\mathrm{yy}}=\mathrm{C}_{\mathrm{xy}}=\mathrm{C}_{\mathrm{yx}}=0 & \mathrm{P}_{\mathrm{S}}=1000 \mathrm{psi}\left(689.4 \mathrm{~N} / \mathrm{cm}^{2}\right) \\
\mathrm{C}_{\mathrm{S}}=4.0 \mathrm{mils} \text { radial }(.1016 \mathrm{~mm}) & \mathrm{N}=12,500 \mathrm{RPM}
\end{array}
$$

Table ll uil ring seal characteristies for outer ring with and without circumferential groove 


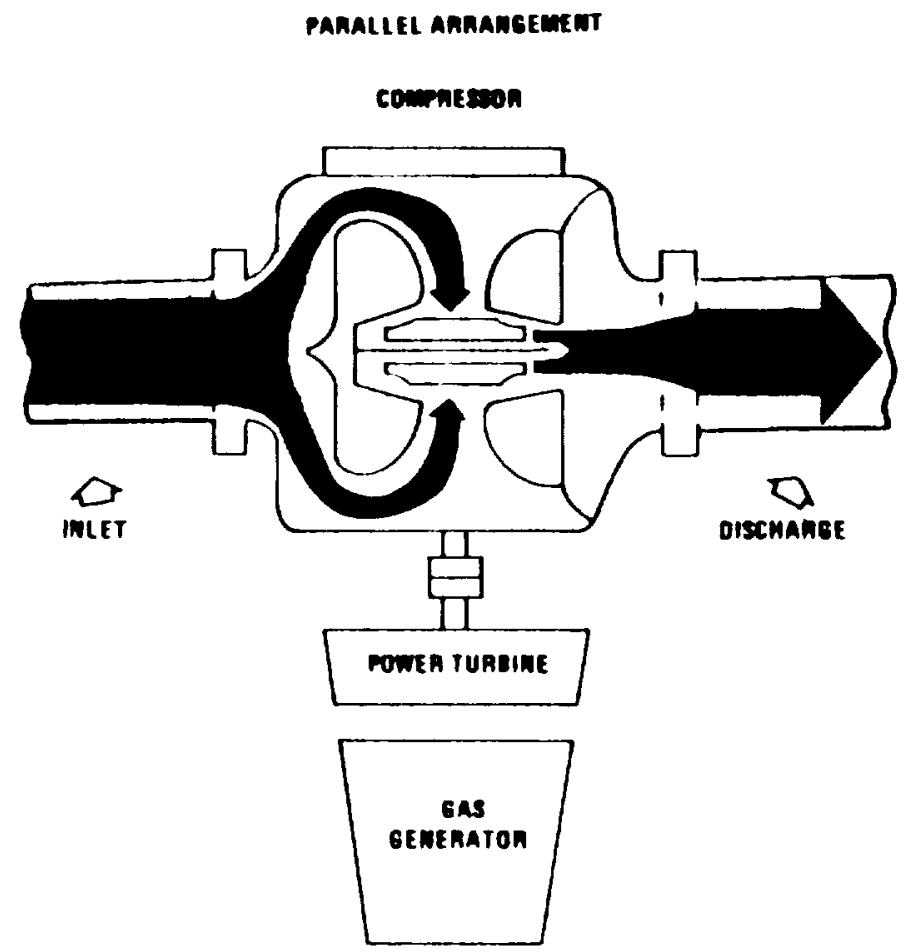

Figure 1 Top view of a single stage parallel flow compressur configuration siatlar to the untes discussed in the text

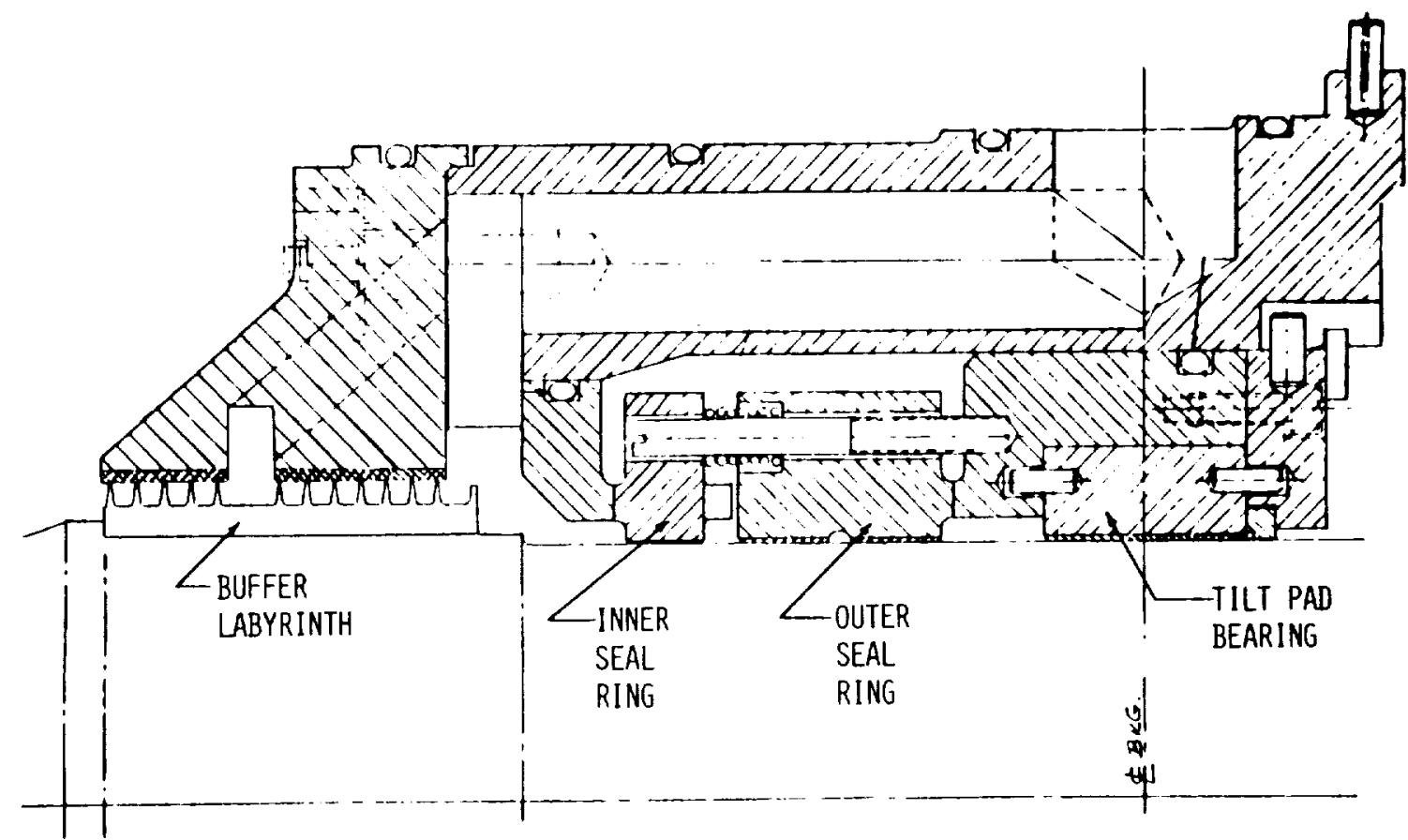

Figure 2 cross-section of bearing-seal cartridge including, the buffer labyrinch 


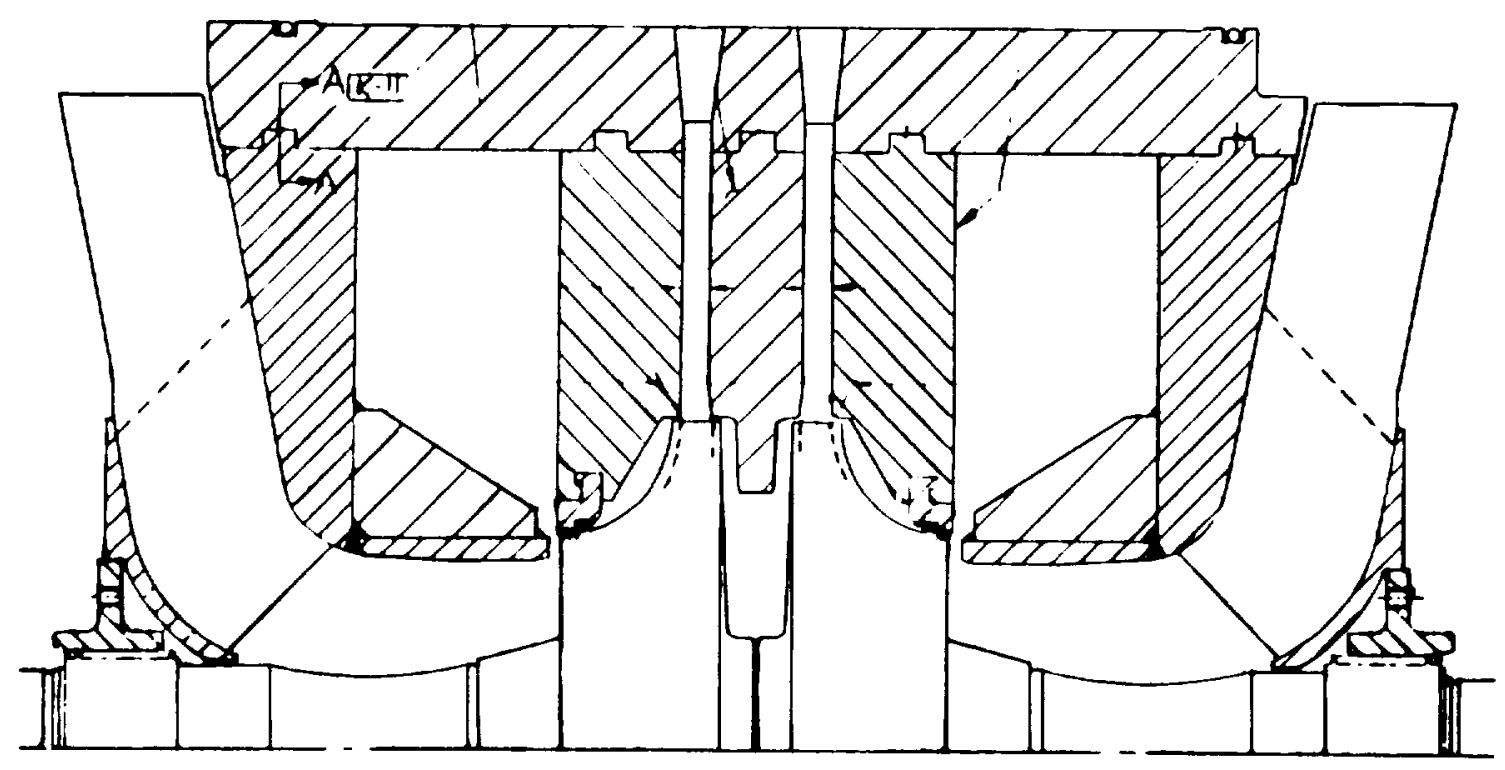

Figure 3 Rotor mid-section showing diffuser elements in cross-section

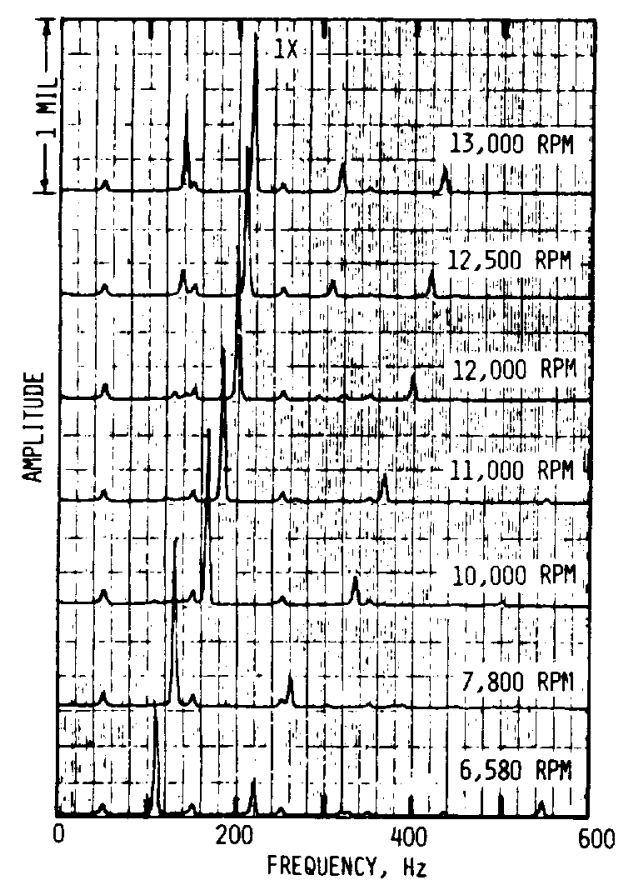

Figure 4 Field data for compressor No. h showing nonsynchronous vibration increasing above $200 \mathrm{~Hz}$ rotor speed

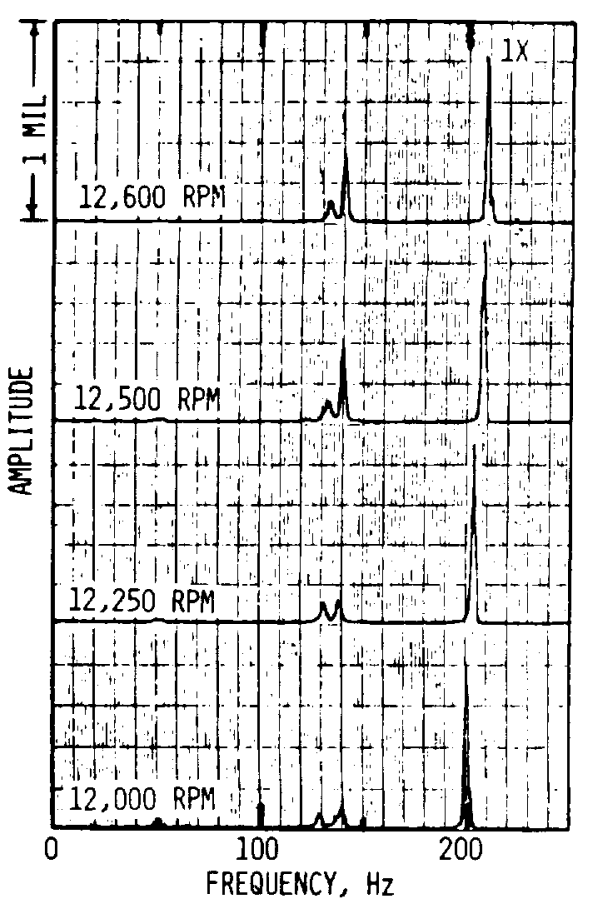

Figure 5 Detail spectrum for compressor 10 o showing $2 / 3$ tracking component moving into fixed $140 \mathrm{~Hz}$ component as rotor speed is increased above $200 \mathrm{~Hz}$ 


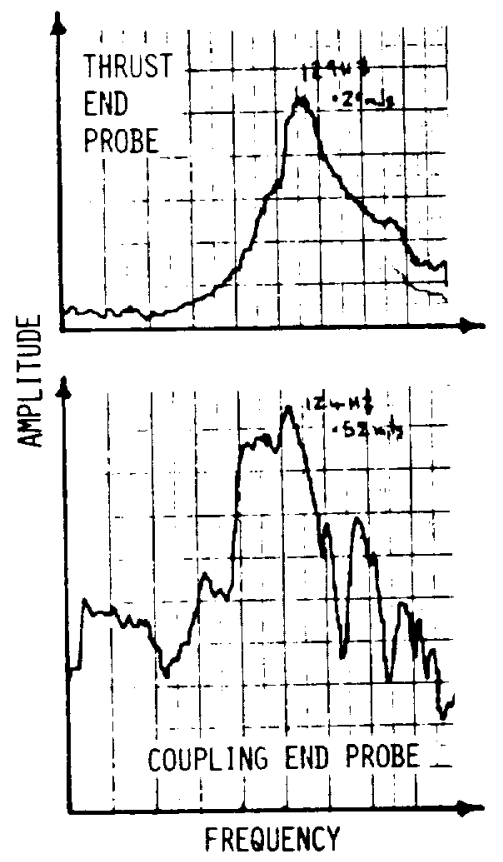

Figure 6 Peak holl response for acie: under ste; pressurization from 95 psi showing peite respurse frequencies of 124 and $129 \mathrm{~Hz}$

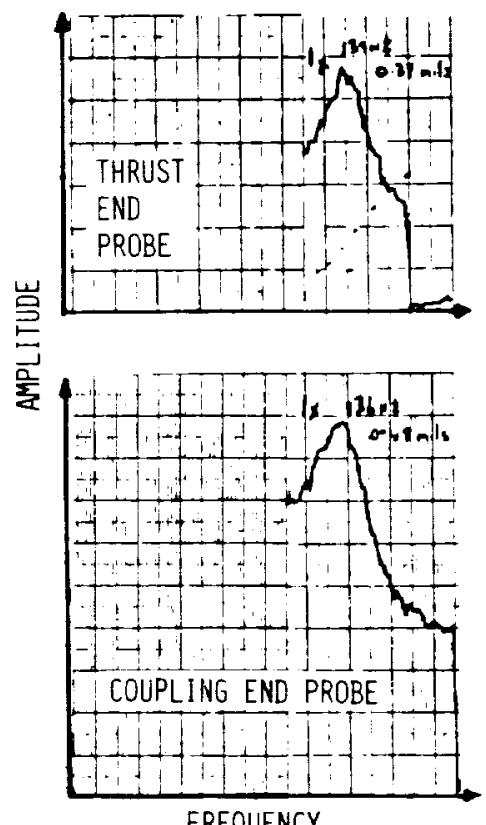

FREQUENCY

Figure 7 leok hold response for moral abcel under full pressure (sol psi) showing increased peak response frequencies of 136 and $139 \mathrm{~Hz}$

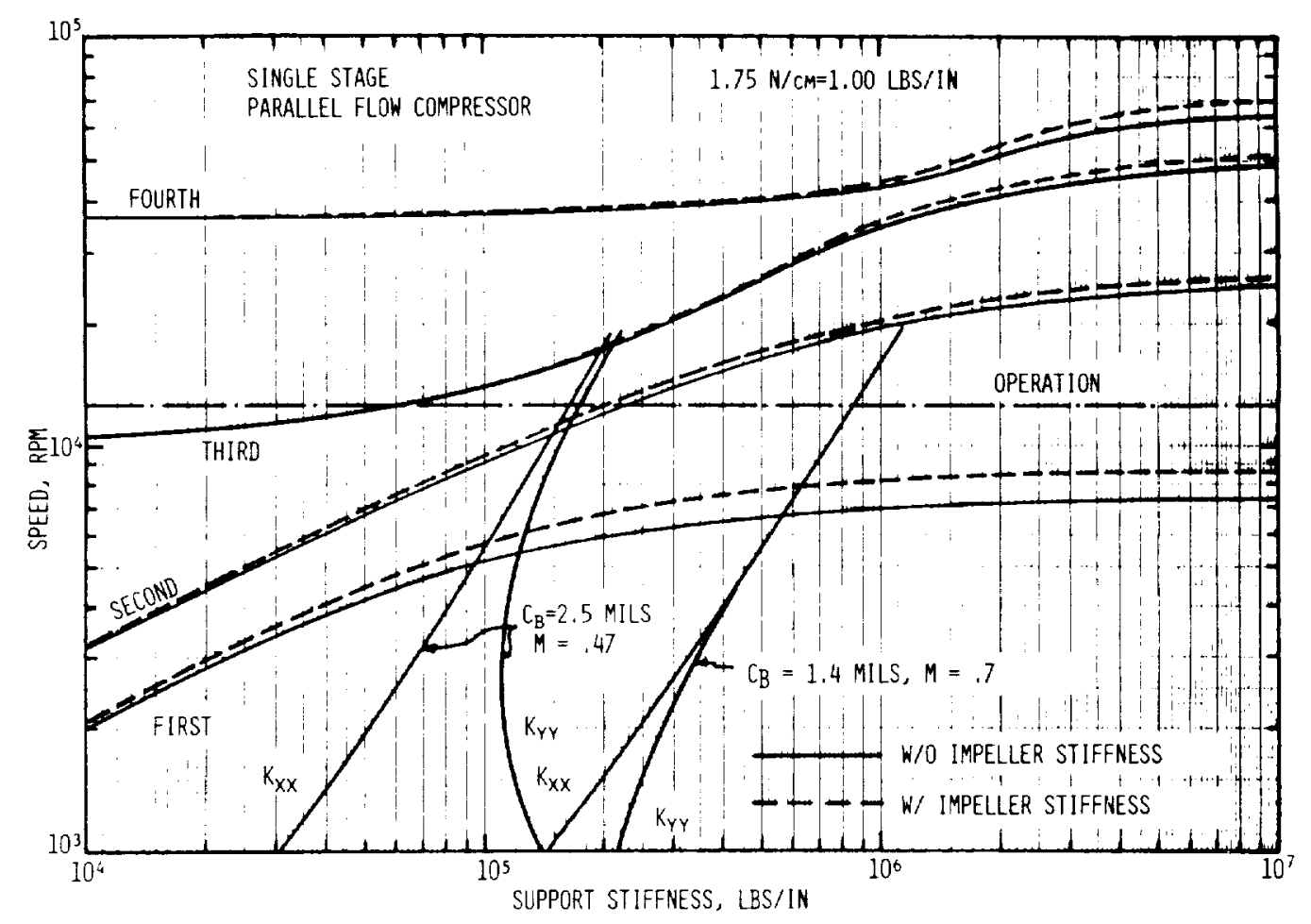

Figure 8 Undamped critical speci map with and without impeller stiffness with new bearing characteristics overplotted 


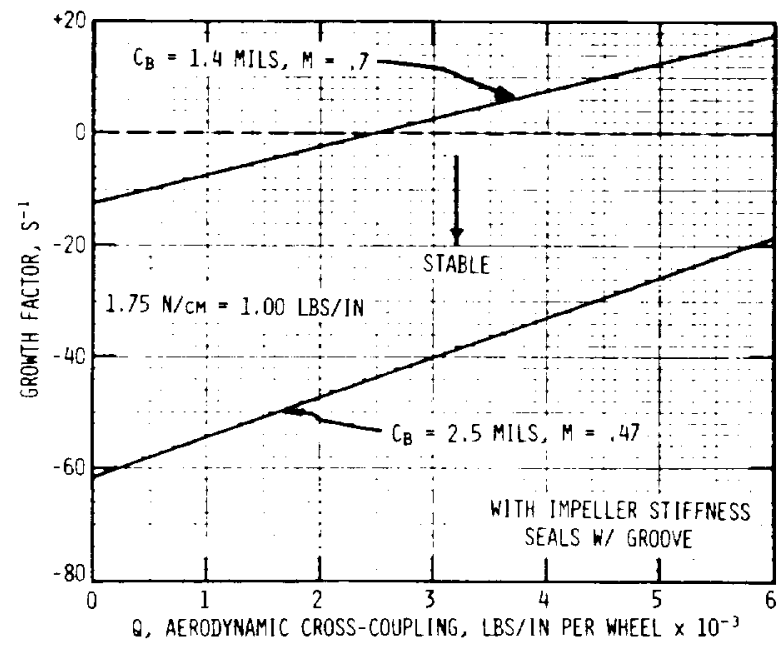

Fipure 9 Stability map for standard design new bearings showing growth factor as a function of aerodynamic crosscoupling per stare

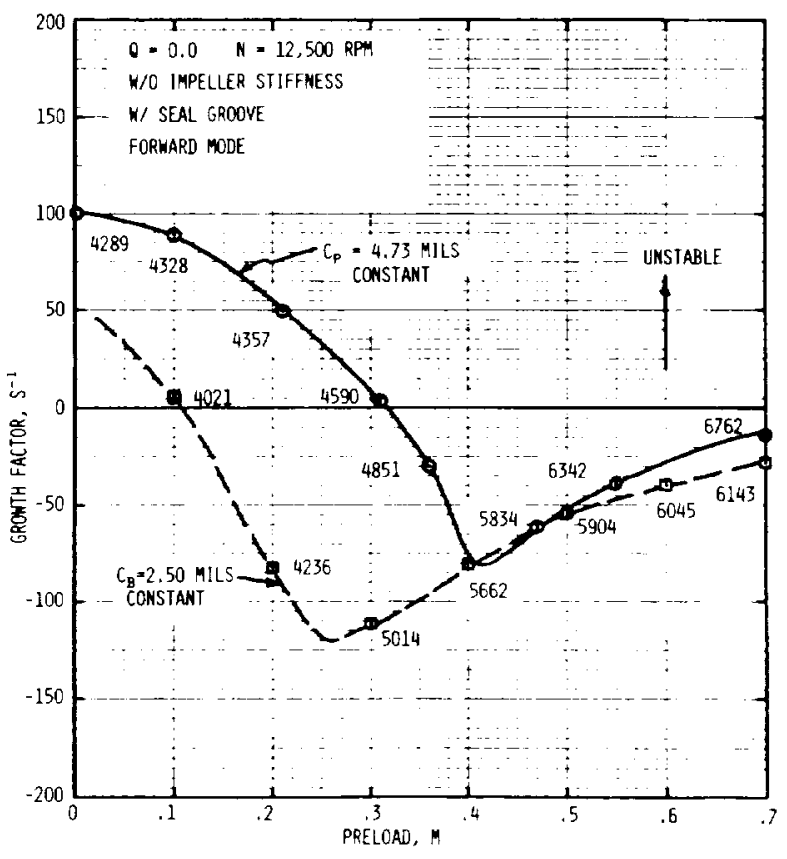

Figure 10 Stablifty map for bearing design variations on preload shuwing optimum for new design $\left(C_{p}=4.73 \mathrm{mils}\right)$ and redesign bearings $\left(C_{B}=2.5 \mathrm{mils}\right)$

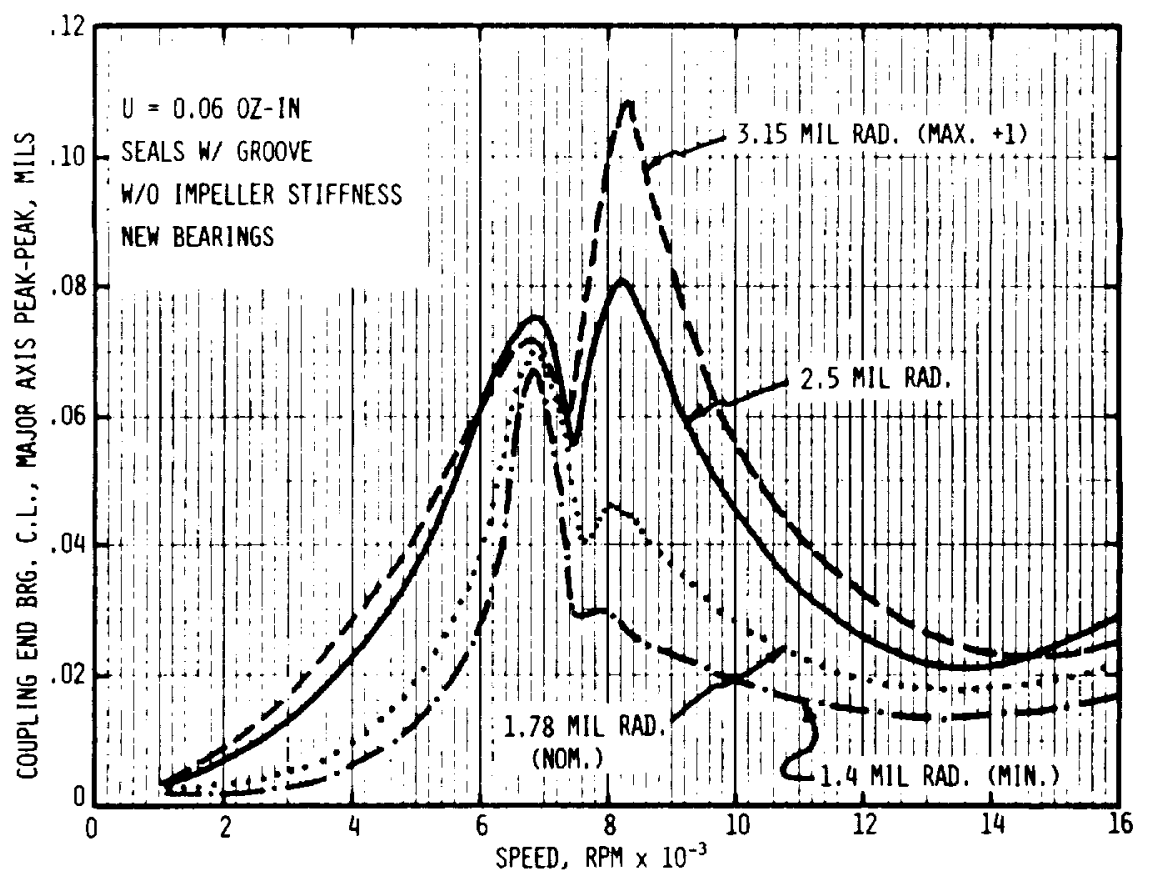

Figure 11 coupling end response versus rotor speed for numeruus bearing clearance values showing response levels increasing above $8000 \mathrm{RPM}$ for incroased clearances 


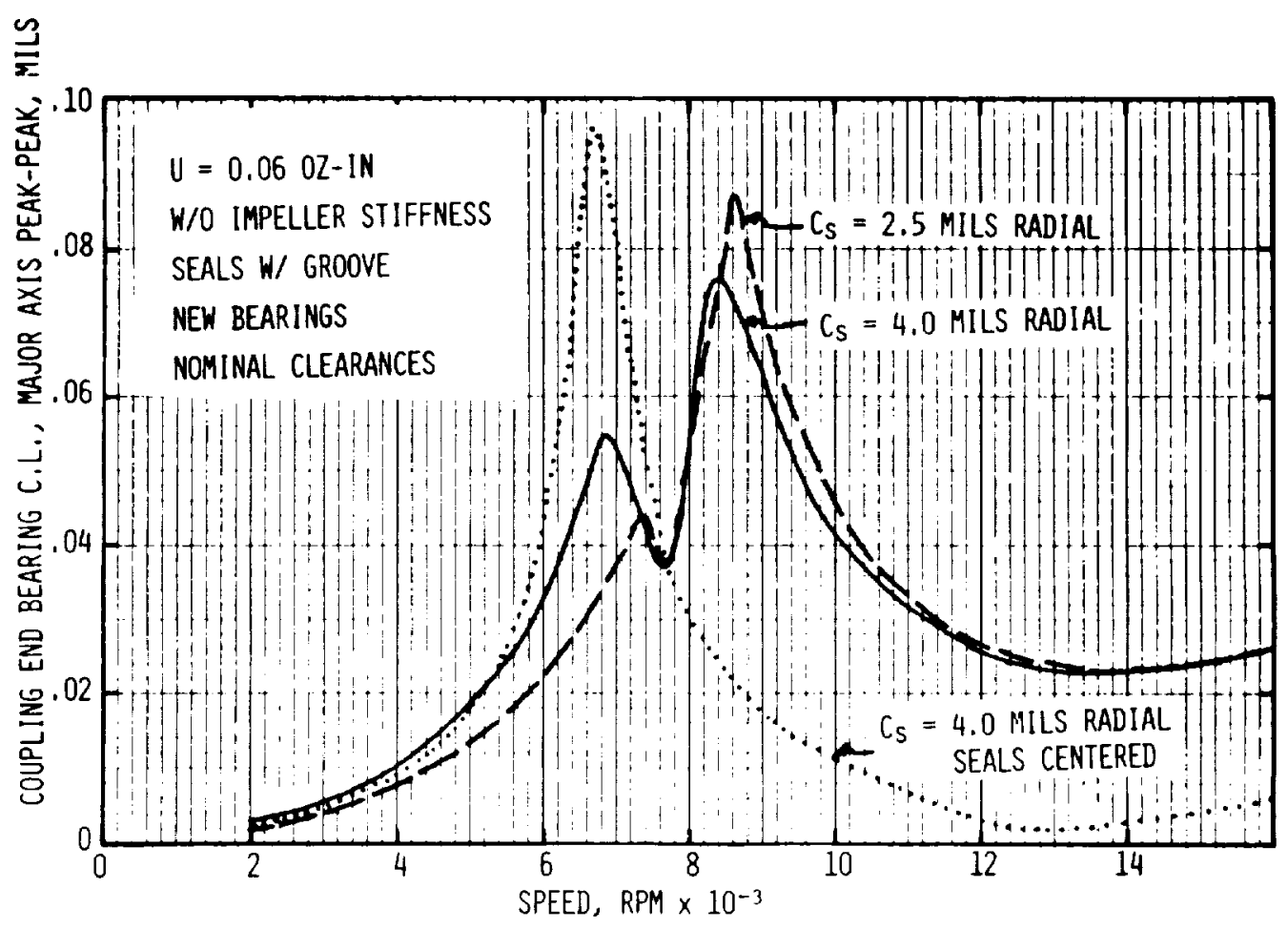

Figure 12 Coupling end response versas rotor speed for numerous seal clearances and operating eccentricity ratios

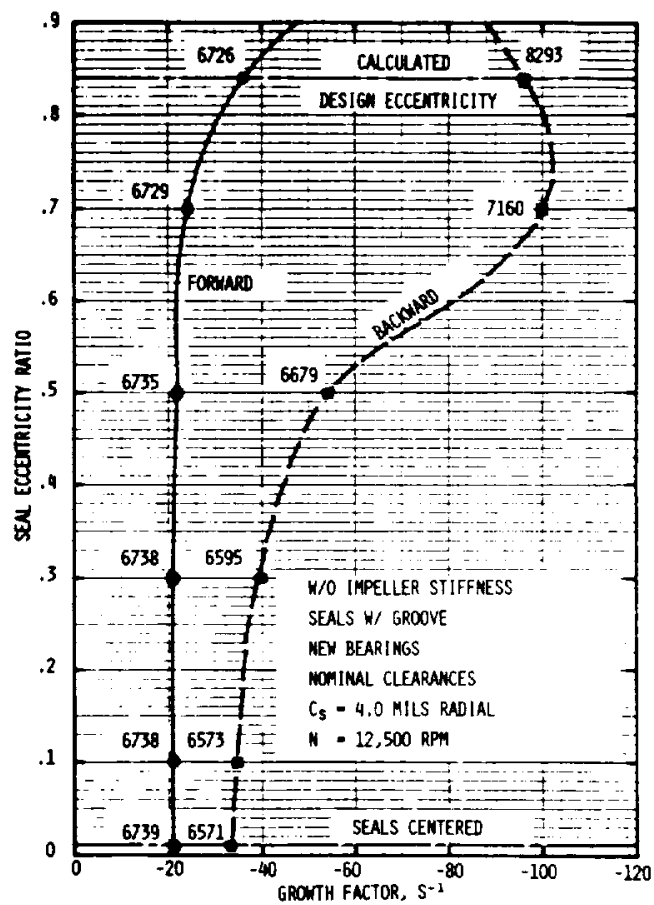

Figure 13 Rotor system stability versus seal eccentricity ratio for new bearing showing improved stability for increased seal eccentricity

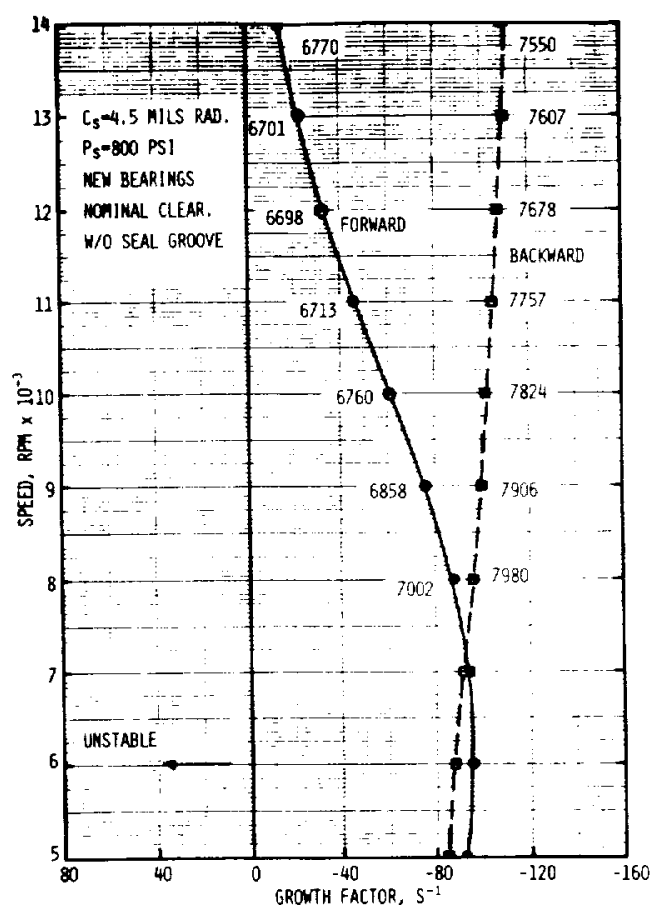

Figure 14 Rotor system stability versus rotor speed for new bearings and seals without circumferential groove showing nearly fixed damped natural frequencies 


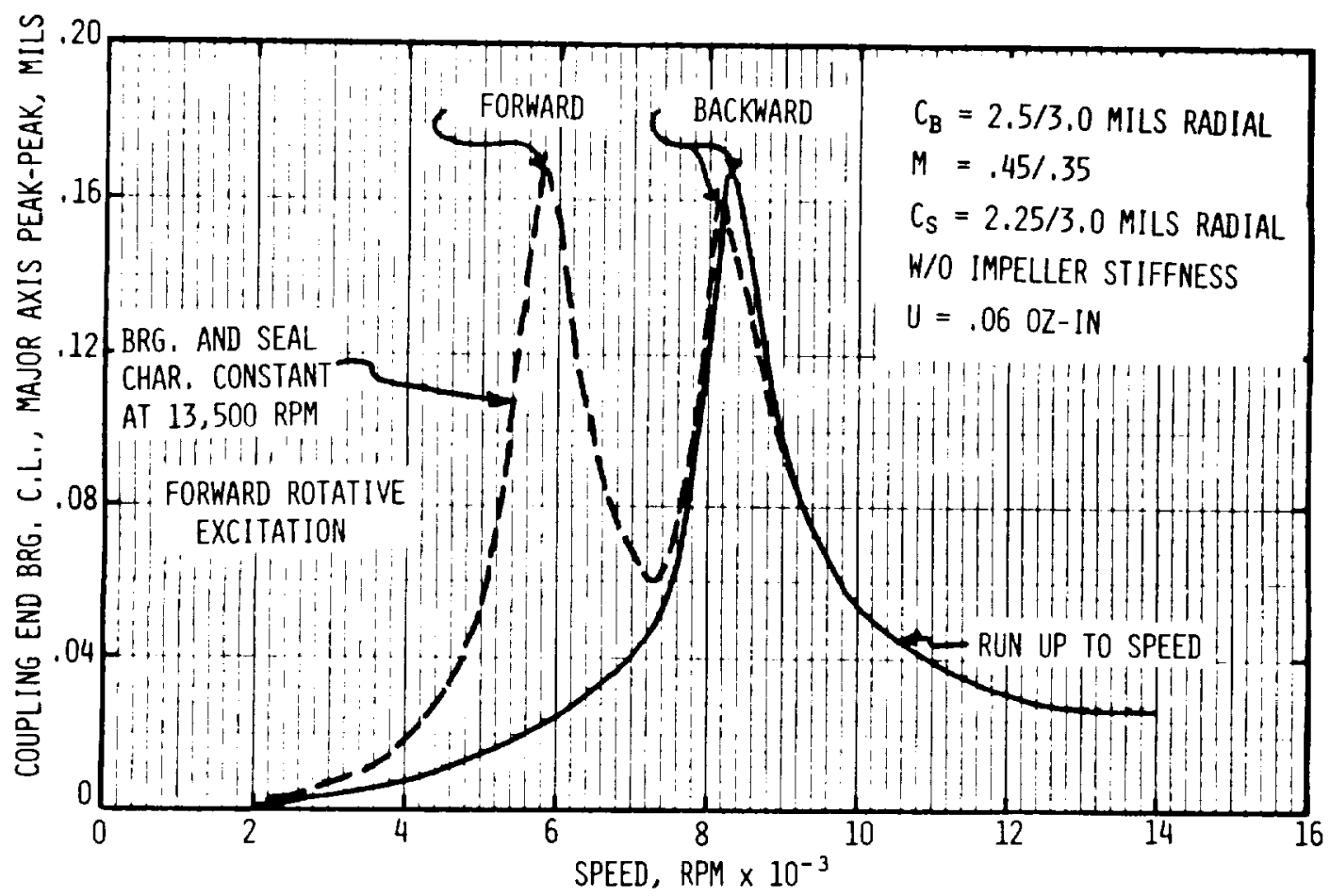

Figure 15 kesponse study showing that both the forward and backward modes may be excited by a forward rotative foroing, function when the bearing and seal charateristics are fixed at values for $\mathrm{N}=13,500 \mathrm{RP} M$

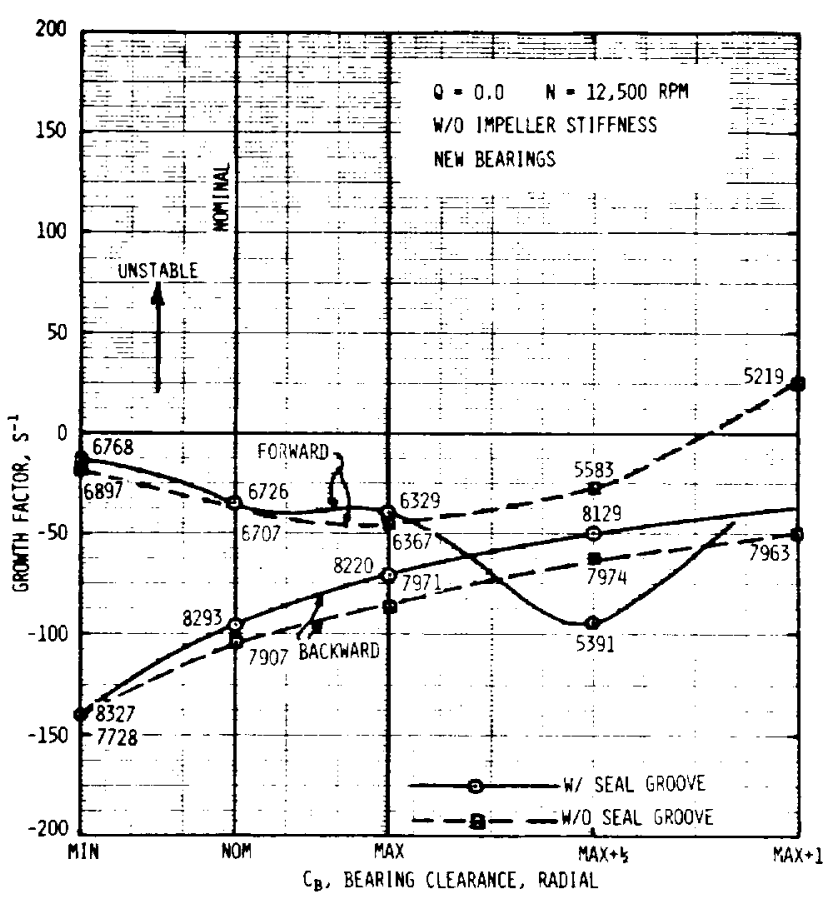

Figure 16 Stability plot showing design optimization study for the new bearings

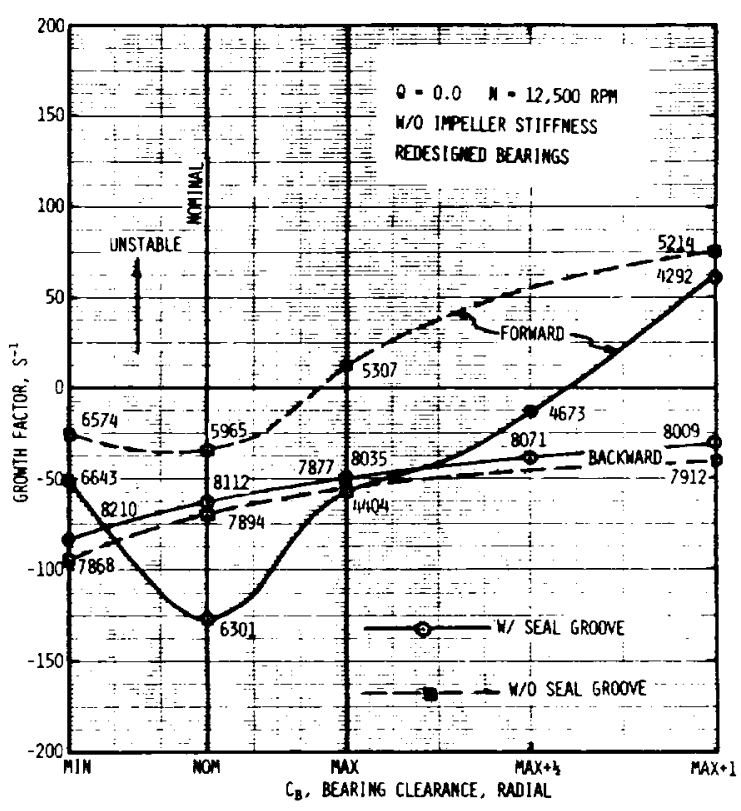

Figure 17 Stability plot showing design optimization study for the redesign bearings 


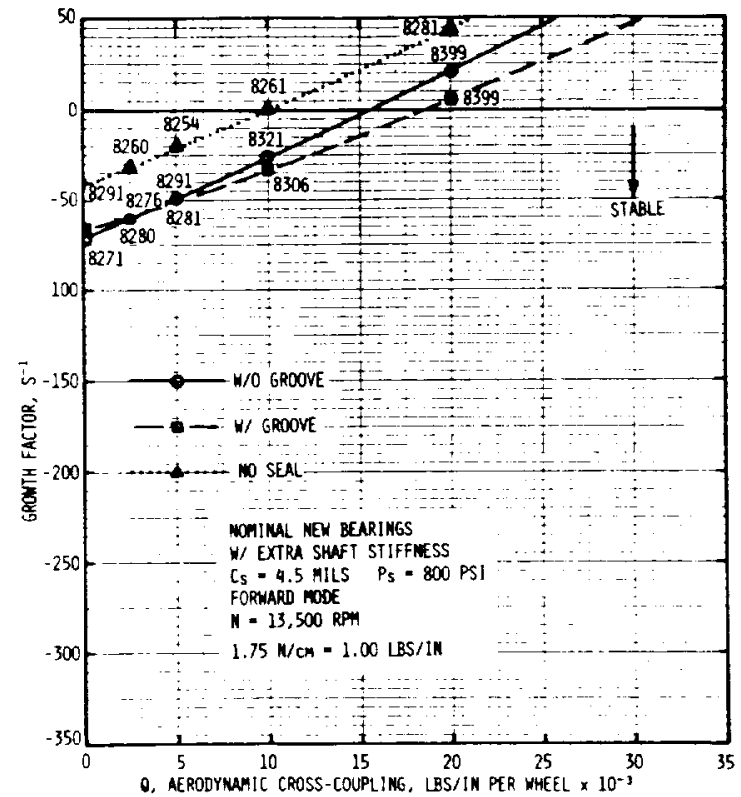

Firure 18 Stability versus aerodynamic cross-coupling for the stiffened rotor system to give the forward mode at $140 \mathrm{~Hz}$ for the nominal new bearing for various oi seal conditions

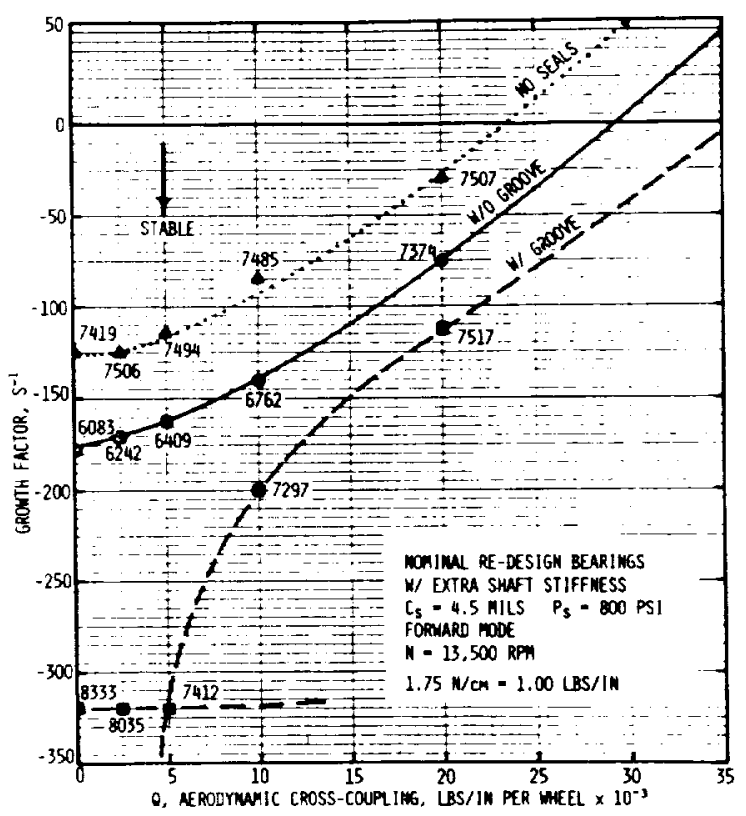

Figure 19 Stability versus aerodynamic cross-coupling for the stiffened rotor system for the forward mode and redesign bearings for various seal conditiuns

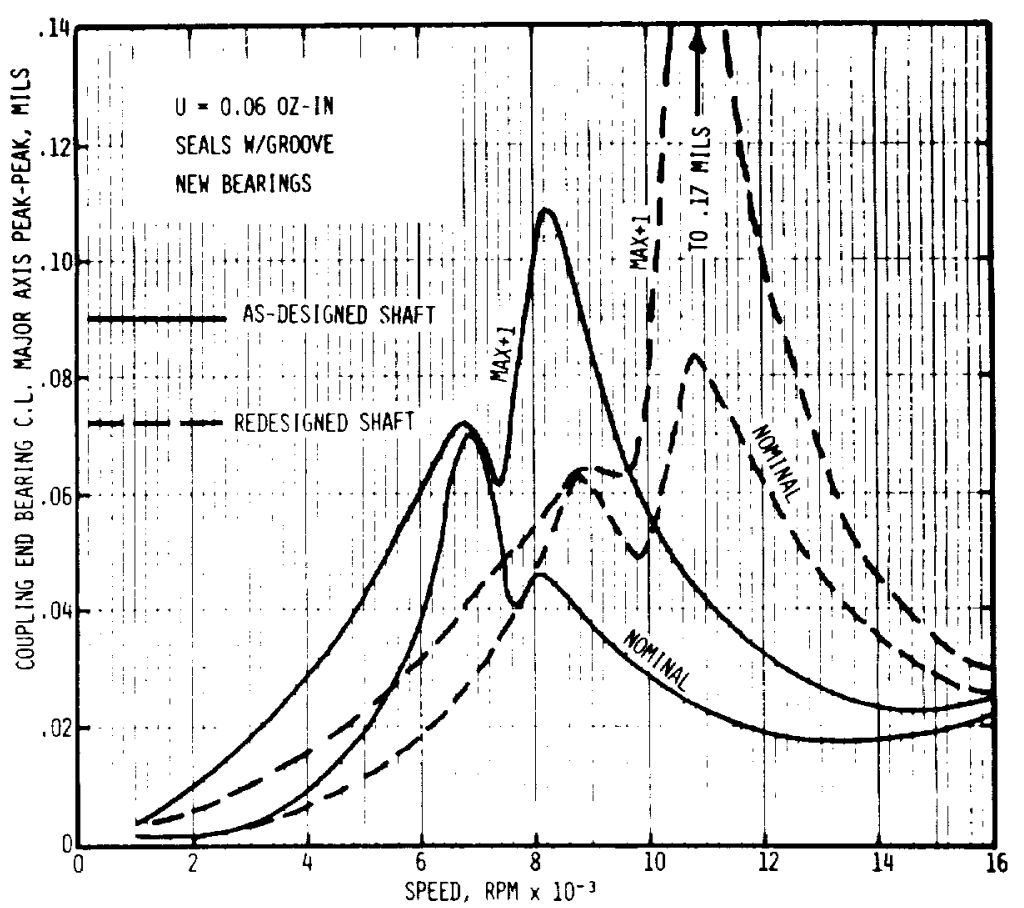

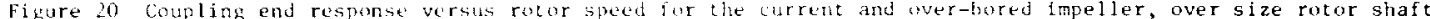

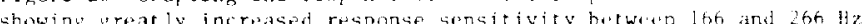




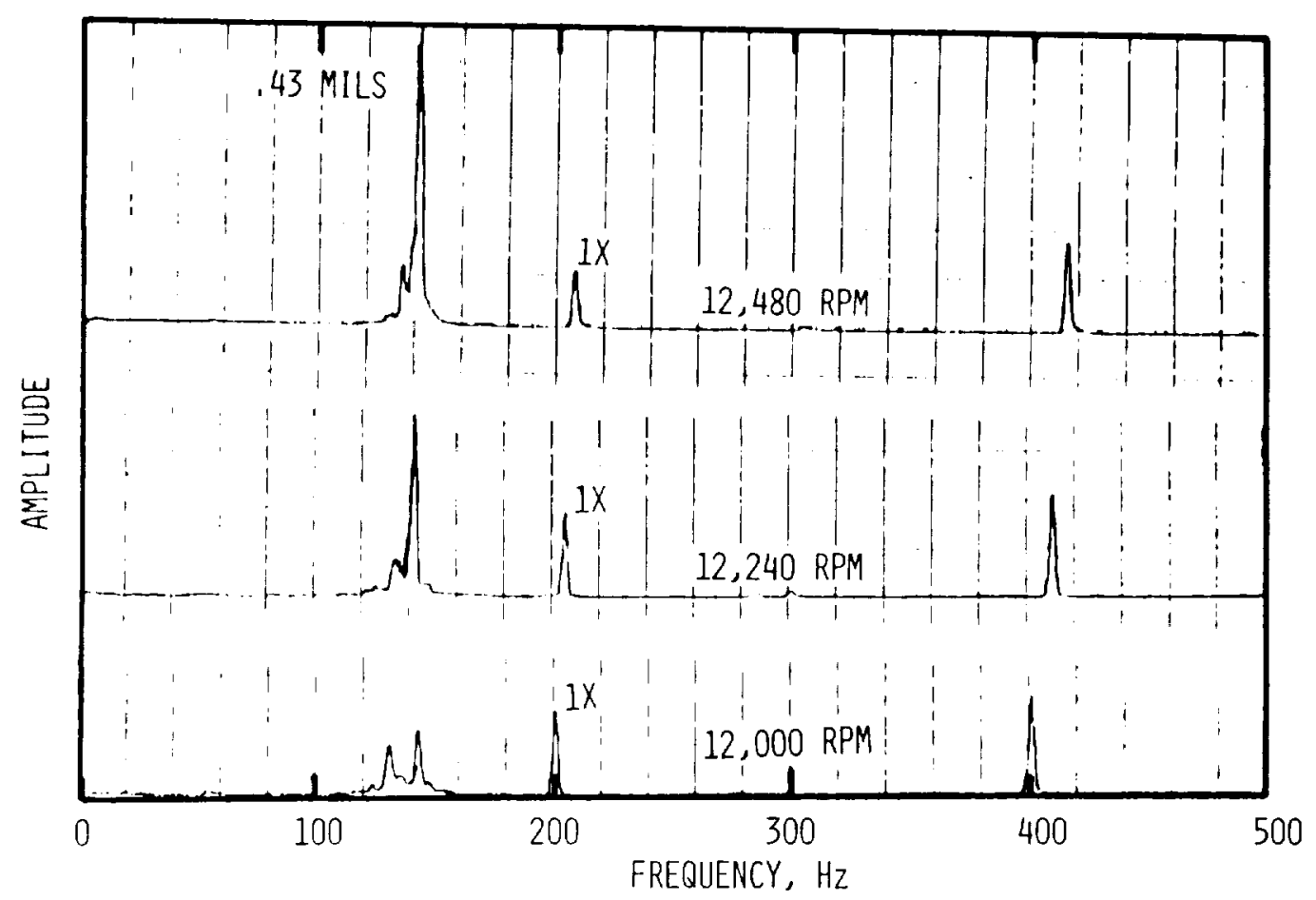

Figure 21 Spectrum for compresser se. F betere the if al design for eliminating the $2 / 3$ tracking component showing rapidly fncreasing sub-synchronous vibration at $14 \mathrm{fl}$

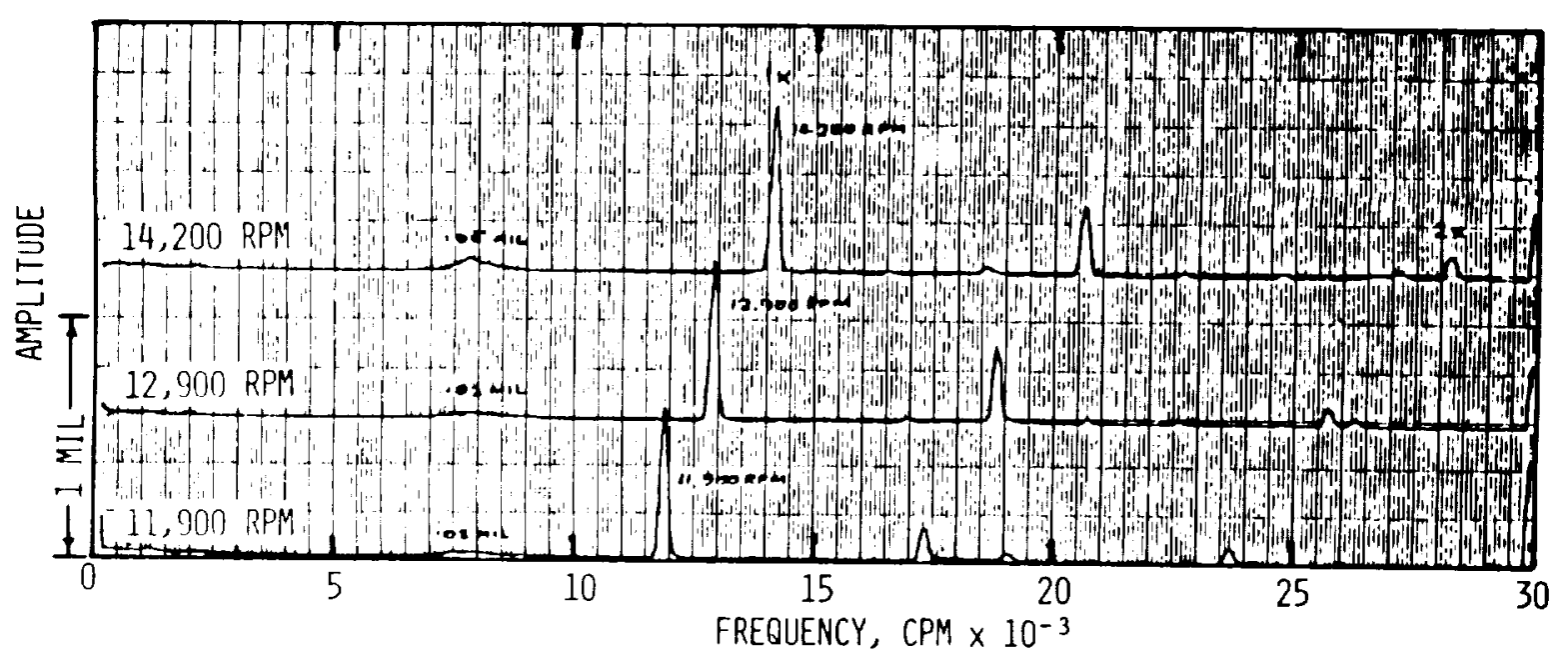

Figure 22 Spectrum for cumpessur No. 5 after final desibn for diffuser showing the total absence of the $2 / 3$ component and a miximum sub-synchronous component of 0.15 mils at fixed frequency 


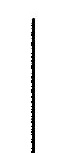

